\title{
Estratégias empresariais e instrumentos econômicos de gestão ambiental
}

\author{
$\star$ Paulo Cesar Vaz Guimarães \\ is Jacques Demajorovic \\ celiac@eaesp.fgvsp.br \\ - Roberto Guena de Oliveira
}

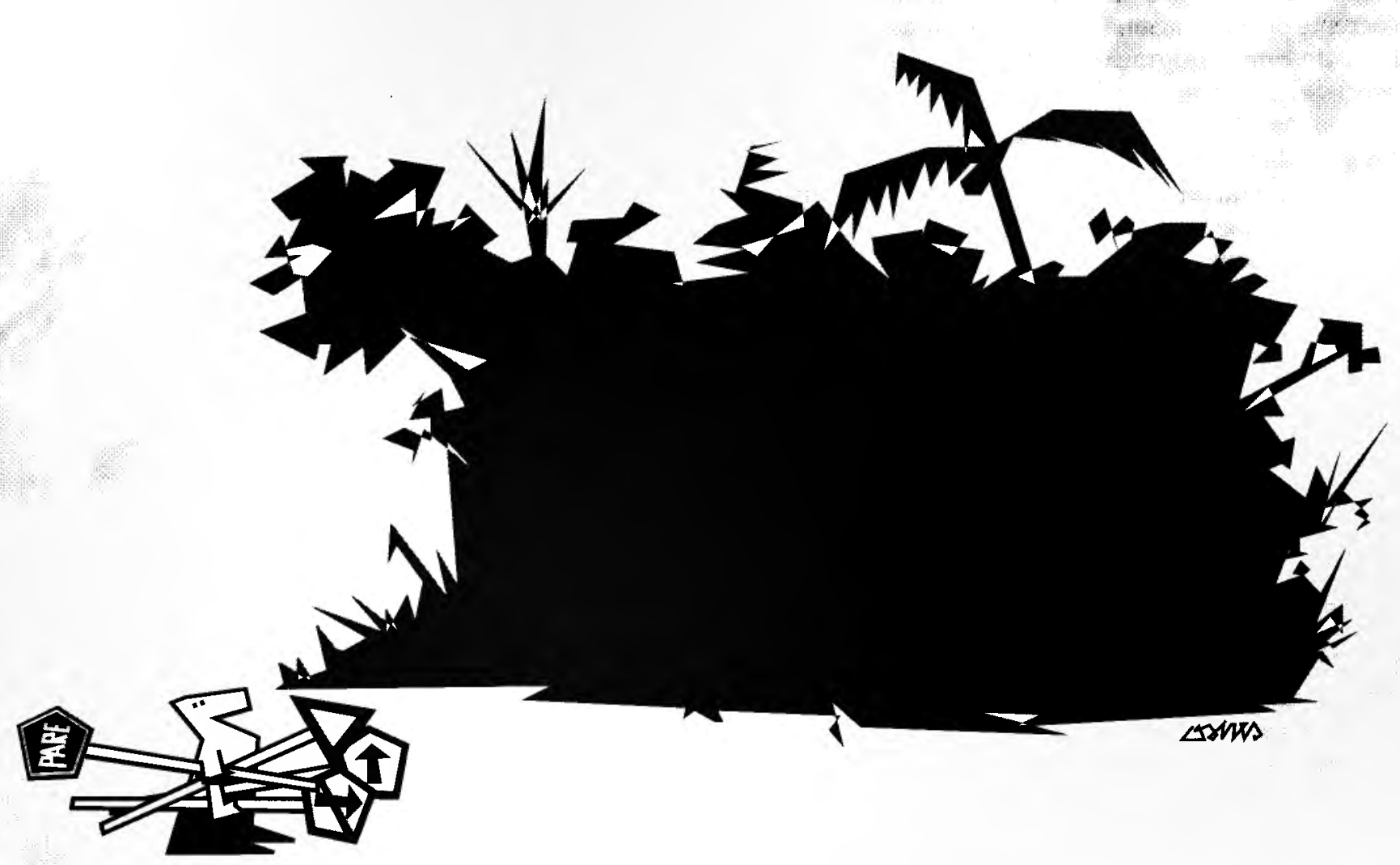

PALAVRAS-CHAVE:

instrumentos econômicos, gestão ambiental, estratégia empresarial, externalidades, formulação de estratégia, intervenção governamental, economia de empresas.

\section{KEY WORDS:}

economic instruments, environmental management, entrepreneurial strategies, externalities, strategy formulation, governmental intervention, company economy.

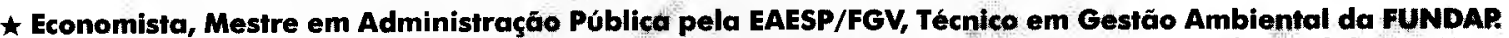 tz Economista, Mestre em Administração Pública pela EAESP/FGV, Técnico em Gestáo Ambiental da FUNDAP \\ - Economista, Mestre e Doutorando em Economia pela USP, Professor do Departamento de Economía da FEA/USP}

(rae@eaesp.fgvsp.br) Assinatura Email 


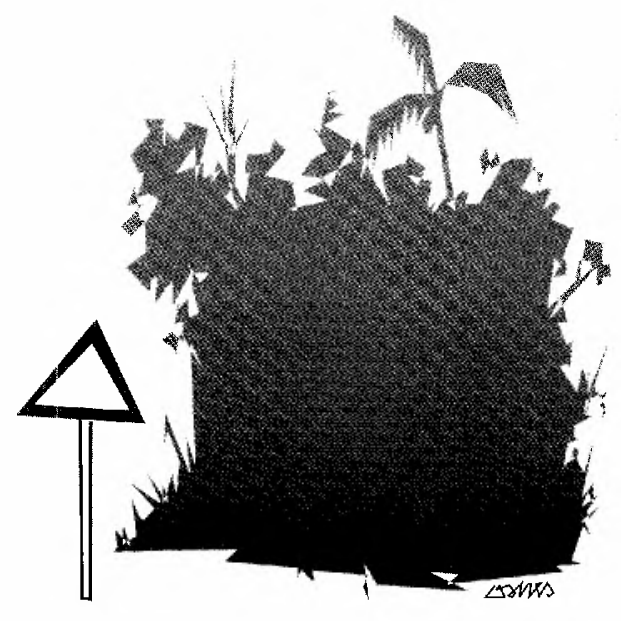

$\mathbf{N}$ o interior das grandes incertezas que caracterizam as duas últimas décadas deste século, uma asserção pode ser colocada: a política a mbiental já transcende o debate sobre os problemas de prescrvação ambiental, estando hoje com o foco direcionado para as questóes de custoefelividade. Ou seja, náo basta a identificaçäo de parâmetros para o controle ambiental e para a manutençäo/incremento dos recursos naturais; requer-se também a avaliaçào do cuslo que a sociedade incorre para a obtenção dos resultados almejados.

As razões que explicam as transformações são diversas, mas essencialmente derivam do fato de as estratégias anteriores, calcadas na pretensa capacidade absoluta do poder público de gerir a dinâmica econômica, terem se mostrado falhas. Em largos traços, podese caracterizar as primeiras fases da política ambiental como um jogo onde os atores mal conheciam o objeto de disputa e, atć cm razão disso mesmo, não conseguiam condensar as regras básicas. A contenda tornava-se muitas vezes infrutífera, pois os avanços e recuos dos grupos acabavam refletindo-se na deterioraçāo ambiental. Com o aprendizado adquirido ao longo do processo, associado às pressóes exercidas pelos movimentos sociais e pelos consumidores, mais a crise de governabilidade que aflige o Estado moderno, novos arranjos passaram a ser implementados. Como mote, em todos cles está presente uma regulação pública eficaz que permita maior flexibilidade aos agentes conômicos de tal sorte que propicie melhor qualidade ambiental a um custo menor.

Nesse cenário, uma tendência recorrente que se nbscrva é a procura de novos instru-

\author{
Os instrumentos econômicos de gestão \\ ambiental podem assumir um novo papel na \\ realidade brasileira: subsidiar as empresas na \\ formulação de suas estratégias.
}

\author{
The economic instruments of environmental \\ policy can assume a new roll in Brazilian \\ reality: to influence the companies in \\ formulation of theirs strategies.
}

mentos de gestão ambicntal. Particularmente no contex to dos países desenvolvidos, os denominados instrumentos conomicos estão adquirindo relevância. No caso brasileiro o assunto é incipiente', mas declarações de autoridades, tanto na esfera federal quanto estadual, sinalizam que o tema está entrando na pauta governamental. No início deste ano, por excmplo, o ministro do Meio Ambiente, dos Recursos Hídricos e da Amazónia Legal, Gustavo Krause, definiu o estabclecimento de um sistema de taxação ambiental para garantir maior racionalidade no uso dos recursos naturais e no controle da poluição . Já no âmbito do Fstado de São Paulo, o governador Mário Covas está realizando estudos para implementação de um sistema de cobrança pelo uso da água ${ }^{3}$.

As mudanças que estão sendo delineadas necessitam ser discutidas cntre os diversos grupos de interesse, visto que suas implicações não serão de pequena monta. No conjunto, o setor privado deve estar preparado, pois, afora afetarem diretamente as estruturas de custo, a classe empresarial possui um papel central na gestão ambiental, conforme definido pela Agenda 214. E, ao contrário de uma visão simplificada muito difundida, que acredita na total harmonia entre ação empresarial e meio ambiente, o caminho a ser percorrido é bastante conflituoso e demandará intensas negociações.

Este trabalho contribui para uma reflexão sobre as características que poderão se consolidar na realidade brasileira, de subsidiar as empresas na formulação de suas estratégias. O primeiro segmento aborda a natureza da intervenção governamental no funcionamento dos mercados, justificando a apli-
1. É corto que existenı unstrumentos económicos na atıal política ambiental brasileira. mas anda exercem um papel secundário Ver REIS. E SEROAA DA MOTTA. R. ThE application af economic instruments in environmental policy the Brazilian case Revista Brasileira de Economia, Rio de Janeiro v. 48 n. 4 , p. 551 75,1994

2. MENDES. V Krause anuncia medidas para conter poluição. OEstado de S. Paulo, São Pau$10,2203-1995$

3. CARLINALII R Covas propóe novo mnoslo sobte uso de agua follia de 5 Paulo 29 03-1995 Para maiores detathes ver GUIMARÁES, P Instrumentos econömicos para gerenciamento ambiental: a cobranca pelo ıso da áqua no Estado de Sào Paulo RAE -Revista de Admimstração de Empre. sas. Sào Paulo v 33, n. 5, p. 88-97, 1993.

4. UNITED NATIONS Report of the United Nations Conference on Environment and Deve. lopment. Rio de Janeiro: UNO. 1992. 


\section{Os instrumentos de comando e controle, embora tenham representado substancial progresso na política ambiental, são criticados por não atingirem muitos dos objetivos nos prazos estipulados, serem de difícil aplicação e, muitas vezes, economicamente ineficientes.}

cação dos instrumentos de gestão ambiental, e apresenta as principais modalidades que estão sendo utilizadas nos países desenvolvidos. Em seguida, discute-se o posicionamento das empresas em face dos instrumentos econômicos, para então concluir com algumas considerações sobre as perspectivas futuras.

\section{NSTHUMENIGS Lf SESTAO AMBIENTALE SUA MELEACAO}

O notável crescimento na degradaçăo dos recursos ambientais que se observou nas últimas décadas advém, em larga medida, da incapacidade dos sistemas econômicos modernos de garantir e estimular o uso eficiente desses recursos. Essa incapacidade deriva basicamente da inexistência de mercados para grande parte deles: ar puro, água limpa, biodiversidade etc. são bens que possuem valor econòmico - as pessoas estariam dispostas, em princípio, a pagar algo por eles , mas que não podem ser comprados e vendidos como uma mercadoria qualquer. Entre as causas da inexistência desses mercados, pode-se destacar: a indefinição dos direitos de propriedade sobre os recursos naturais, ou seja, a indefinição acerca de quem é o vendedor e quem é o comprador desses recursos, $\mathrm{e}$ a impossibilidade de se restringir seu consumo a um conjunto delimitado de agentes não é possível proibir, por exemplo, que o ar puro seja consumido por alguém que não tenha pago por ele ${ }^{5}$.

As principais conseqüências da inexistência de mercados para os recursos naturais são sua alocação ineficiente e as exterioridades negativas.

Diz-se que há uma exterioridade negativa 5. PEARCE, D., WARFORD. J. World without end: eco nomics, environment and sustainable development. New York: Oxford University Press, 1993 de bem-estar ou pela redução na produtividade de outras empresas causada pela poluição. Não tendo que interiorizar o custo provocado por sua poluição, a empresa acabará poluindo além daquilo que seria ótimo do ponto de vista social.

$A$ alocação ineficiente de um recurso natural escasso é uma conseqüência da falta de mercado para ele. Isso fará com que o recurso não seja necessariamente destinadoaos usos prioritários para a socicdade.

A política ambiental tem como objetivo eliminar ou, ao menos, reduzir essas duas fontes de ineficiência. Basicamente, duas estratégías podem ser adotadas: a adoção de instrumentos de comando e controle e o uso de instrumentos econômicos. A primeira consiste em impor aos agentes econômicos normas para o acesso e o uso dos recursos naturais. Já os instrumentos de incentivo econômico procuram empregar sinais de mercado (preços, taxas e subsidios) para induzir os agentes ao uso eficiente desses recursos.

$\mathrm{Na}$ abordagem de comando e controle, o governo especifica os padrōes e a quantidade de poluentes que podem ser dispostos no meio ambiente, muitas vezes também indicando a tecnologia considerada mais apropriada para alcançar esses objetivos. Além disso, é usual o estabelecimento de prazos para que os padrōes sejam cumpridos e multas para quando os objetivos não são respeilados. A maior vantagem deste cnfoque ê prover o regulador com um grau razoável de previsibilidade quanto aos níveis de redução da poluição. Segundo alguns de seus defensores, este sistema também assegura a competiçāo no mercado, uma vez que as obrigaçôes săo iguais para todos.

Os principais mecanismos da política de comando e controle são: normas e padrões, licenças e permissóes e controle do uso do solo e da água. Dentre estes, as normas e padrôes têm sido mais utilizados na regulação ambiental em países desenvolvidos e em desenvolvimento. Flas definem os objetivos ambientais e estabelecem as quantidades de concentração de substâncias que podem ser lançadas no ar, água e solo, ou que eventualmente estejam contidas em uma mercadoria. As normas e padrões deste gênero são classificadas da seguinte forma: padróes de qualidade ambiental, padrões de emissão, padröes tecnológicos, padrōes de processo e padrões de produto. É importante ressaltar que a existência das normas e padrōes pressupõe a possibilidade de monitoramento por parte das autoridades que têm o poder de impor mul- 
tas aos infratores. Quando esse poder de enforcement $t^{6}$ não existe, o único incentivo para o cumprimento das normas é a consciência social ou a exigência do próprio mercado?

Os padróes de qualidade ambiental estabelecem a concentração máxima de poluentes que podem ser lançados no meio ambiente. São, por exemplo, especificações da quantidade mínima da concentração de oxigènio em determinado ponto de um rio. $\mathrm{O}$ objetivo básico é garantir o nível mínimo da qualidade ambiental do ecossistema. As desvantagens desta alternativa são duas: primeiro, quando os padrões não são observados devido à emissão maior de poluentes, é difícil identificar a principal fonte geradora do problema; segundo, o conhecimento existente nem sempre é suficiente para precisar os efeitos negativos dos poluentes sobre o homem, animais e plantas.

Os padrões de emissáo informam a quantidade máxima de concentração de poluentes lançada por uma fonte específica. São cstabelecidos para uma planta industrial como um todo ou para os diferentes focos de emissão presentes em uma única empresa. E normalmente são categorizados em padrões tecnológicos e padróes de desempenho. No primeiro caso, a tecnologia é estipulada para que as firmas cumpram as determinaçōes ambientais. No segundo, o governo adota uma medida de desempenho (volume ou concentração de poluentes que podem ser emitidos), com flexibilidade para que os poluidores escolham as alternativas que considerem mais eficientes. As leis sancionadas para controle de emissão dos veículos são um exemplo da sua aplicação prática. Os padrões de emissão, de maneira geral, fornecem meios para um controle da poluiçăo com razoável grau de previsibilidade, particularmente no que diz respeito ao controle da qualidade da água. Certas desvantagens, contudo, lambém são observadas. A uniformidade de padrōes, ao não levar em consideração as especificidades de cada rio, por exemplo, tende a provocar uma proteção exagerada em alguns cursos de água e deficiente em outros. Acrescente-se ainda que a política de monitoramento e $t n$ forcentent exige clevados custos administrativos e financeiros.

Os padrões de produtos e processos estabelecem requisitos mínimos com relação às substâncias contidas em um produto e à tecrologia empregada em sua elaboração. Exemplos de padrão de processo são a proibição do uso de dinamite e a especificação de um tamanho mínimo para a malha da rede

na pesca, enquanto a restrição ao chumbo na gasolina é um exemplo de padrāo de produto. Apesar de o banimento de produtos parecer uma medida muito rigorosa, pode ser eficiente quando se trata de produtos altamente tóxicos ou que têm substitutos acessíveis.

As licenças e permissōes estão normalmente conectadas à política de controle da qualidade do ar e da água. As condiçōes específicas para obtê-las variam de país para país. No entanto, algumas podem ser consideradas básicas: obediência a formas específicas de procedimento; escolha de local que minimize os impactos ambientais e econômicos; instalação de planta de tratamento ou equipamento de controle de poluição em um prazo de tempo determinado; e adoção de outras medidas de proteção ambiental. Unn ponto favorável está na possibilidade de se retirar ou suspender as licenças sempre que haja um outro interesse com maior prioridade.

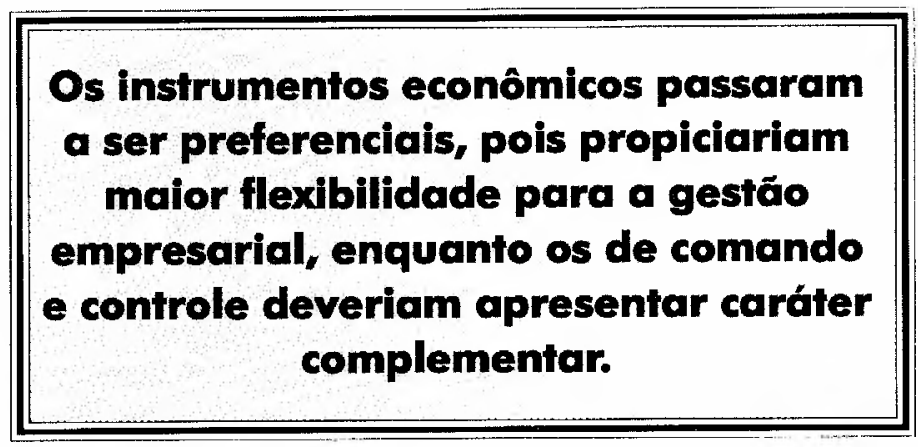

Cabe notar que esta opção implica o pagamento de uma taxa que eventualmente pode ser usada para cobrir os custos dos programas de controle de poluição.

Os controles do uso da água e do solo săo aplicados geralmente em nível local, como instrumentos de preservação ambiental. $\mathrm{O}$ zoneamento pode impedir que indústrias poluidoras se localizem em áreas não-apropriadas ou controlar a densidade popula cional. A legislaçāo brasileira é um exemplo, ao estabelecer programas de zoneamento para áreas poluídas consideradas críticas nas principais metrópoles e regióes industriais do país. O maior problema está na vulnerabilidade em face da pressão política e econômica, o que muitas vezes pode levar a um desrespeito dos objetivos ambientais.

Os instrumentos de comando e controle, embora tenham representado substancial progresso na politica ambiental, são criticados por não atingirem muitos dos objetivos nos prazos estipulados, serem de difícil apli-
6. O termo enforcement nẫo possui um equivalente adequado na língua portuguesa. Uma noção próxima è a capacidade do poder público de fazer cumprir a lei.

7. A tipologia dos instrumentos de gestão ambiental está baseada em BERNSTEIN, J. Alternative approach to pollution control and waste management: regulatory and economic instruments. Dis cussion Paper. Washington: World Bank, 1991. 
cação e, muitas veres, economicamente ineficientes, A agenca reguladora necessita de informaça detalhada dos diversos processos produtivose das várias alternativas de controle de poluiçào disponíveis. O custo para determinar todas essas informações, nu que se refere aos recursos necessírios e ao tempo empregado, é muito alto. Soma-se a isso o fato de a padronizaça da tecnologia em diversos setores industriats náo gerar incentivos para a rediçầ a poluiçác e para a busea de toncas nenos poluentes ua mais custo-efetivas Estacategoria de instrumento também se mostra ineficiente no entrentamento de problomas de grande importância, como ficou demonstrado pela halia de resul tados efetivos ma recente conferência sobre o clinta em Berlim.

Como allernaliva para aumentar a eficiencia da gestão ambiental, nos últimos anos muitos paises têm adotado instımentos económicos. O fenomeno e particularmente visível ao longo dos anos 80. Embora tradicional na teoria conomica, e coniando com algumas experièncias práticas esparsas, a opçăo por uma nova estratégia foi disseminada quando fatos como a deterioração da qualidade de vida nos centros urbanos e os grandes acidentes de Bhopal o do Fxxon-Valdez demonstraram que ó modelo de regulação hogemónico não estava conseguindo prevenir nem corrigir us problemas ambientais. A partir daí, a pressão de fortes movimentos sociais e dus próprios consumidores passou a exigir transiomaçoes na politica ambiental".

O primeiro estudo que procurou sistematizar de forma abrangente as inúmcras alternativas que estavam sendo testadas e/ou aperteiçoadas foi patrocinado, em 1987, pela Organização para a Couperação e Desenvolvimento Fconômico (CCDE) ${ }^{10}$. Após identificar mais de cem tipos de instrumentos econòmicos cm uso nos palses-membro, concluilu-se que uma parcela intima proporcionava alguma forma de mudança no comportamento dos agentes ceonòmicos. Um dos fatores que explica a dibilidade ó que mesmo na concepçâo não existia preocupaçăo com tal desomperho, mas sim, por exemplo, com a serraça de receitas pana osetor público. Os instrumenios de comando e controle permaneciam, indiscutivelmento; a base da politica ambicontal.

O docunento cilado serviu de referêncid, e mesno de alerta, para a difusão de pesquisas e debates. Com o objctivo de avaliar a real contribuição dos trabalhos e os avanços concretos na prática da administração pública, a
OCDE atualizou o levantamento nos anos de 1992/93'i. Muitos desses mecanismos funcionam como incentivos para que as empresas deterninem a forma mais eficiente e custoefetiva para alcançar os objetivos ambientais. Os principios que os regem tomam por base o instituto do poluidor-pagador e, mais recentemente, do usuário-pagador. No primejro caso, o poluidor arca com o ônus financeiro proporcional às alteraçôes que gera no meio ambiente. No segundo caso, o usuário de algum recurso do meio ambiente deve pagar o custo social total decorrente de seu consumo, inclusive a diminuição da oferta e os custos de tratamento eventualmente necessários. Os instrumentos econômicos incidem diretamente sobre os custos das cmpresas (por exemplo, cobrança sobre o volume e toxicidade de resíduos gerados, permissóes de polunçáo do ar, sistema pagar-porsacola, pay-per-bag, para coleta de residuos sólidos) ou envolvem custos indiretos, como as taxas que recarm sobre os produtos (por exemplo, taxaçào de combustiveis).

Teoricamente, tais instrumentos possibilitam controlar a poluição de acordo com mecarismos de mercado e, portanto, facilitam a desrogulamentação e reduzem a participação governamental. Quando corretamente ulilizados, os resultacios esperados da adoçăo dos incentivos conômicos são a redução de custos, o incentivo a mudanças tecnológicas. maior flexibilidade nas políticas de controle de poluição a geraçấo de receitas.

As modalidades de instrumentos econô micos adotados nos países desenvolvidos são: cobrança, mercado de licenças negociávcis, subsidtios, sistema depósito-restituiçäo incentivos de onforcment. Para efeito deste trabalho serāo focalizadas apenas aquelas categorias sobre cuja aplicaçāo prálica há informaçôes recentes. Dessa forma, o exemplo de cobrança será centralizado na cobrança de poluiçáo e os subsidios c incentivos decuforcment não serão explorados ${ }^{12}$.

A cobrança de poluiçáo estabelece uma taxa a ser cobrada sobre unidades incrementais de poluição. Sua aplicação é particularmente apropriada quando a alteração ambiental pode ser estimada corretamente, e menos adequada quando se pretende garantir un grau de qualidade ambiental. $O$ instrumento incorpora diferentes mecanismos para controlar o processo de degradação, destacando-se a cobrança sobre emissóes e a cobrança sobre produto.

$A$ cobrança sobre emissōes corresponde a uma laxa cobrada com base na quantidade e qualidade do poluente lançado por uma in- 
dústria no meio ambiente. Geralmente, éassociada aos padróes ou permissões com o in tuito de aumentar a eficiência. Em teoria, o uso da cobrança sobre efluentes apresenta uma série de vantagens em relação à abordagem tradicional de comando e controle: funciona tanto como incentivo, para que as firmas invistam em tecnologia de controle de poluição e reduzam custos, quanto como geradora de recursos adicionais, para financiar e estimular as atividades deenforcement. Dessa forma, essa cobrança pode compensar, mcsmo parcialmente, os custos impostos à sociedade. Alguns problemas, contudo, necessitam ser apontados, principalmente a dificuldade, política e técnica, de determinar um nivel de apreçamento que reflita adequadamente o comprometimento ambiental. A cobrança também pode afetar a concorrência inter-regional quando a redução das taxas é empregada para atrair investimentos industriais, penalizando as regiōes que se utilizam deste instrumento para melhorar a qualidade ambiental.

A cobrança sobre a poluição do ar é aplicada em scis países, sendo que o critério mais utilizado consiste na concentração de $\mathrm{SO} 2$ e NOX. A experiência sueca é a mais bem-sucedida, onde as respostas aos incentivos foram além do esperado. Com uma taxa de aproximadamente USS 7 por tonelada de $\mathrm{NO} 2$, incidindo sobre empresas com capacidade acima de $10 \mathrm{MW}$ e produçāo excedente a $50 \mathrm{GwH}$, as emissōes foram reduzidas de 30 a $40 \%$. Os demais países, à exceção de Portugal, também tiveram como objetivo a mudança no comportamento dos agentes econômicos, mas os resultados sāo no múnimo dúbios, visto que não foi possível a avaliação precisa dos impactos.

As receitas propiciadas pela cobrança são destinadas a diferentes propósitos: enquanto no Canadá, Portugal e Estados Unidos vinculam-se ao gasto em controle de poluição, no Japão estão destinadas à compensação dos danos à saúde pública. Na Suécia, por sua vez, as quantias retornam aos próprios pror dutores de energia na forma de descontos.

A cobrança sobre a poluição sonora causada por aviōes é encontrada cm oito países. $O$ valor varia em função do tipo de ruído, peso e modelo de aeronave. A adoção dessa taxa na Alcmanha aparentemente reduziu em $43 \%$ o nível de ruído; nos demais países os resultados são inconclusivos. Na maior parte das experiências, as receitas destinam-sc aos programas de contenção de ruídos.

Uma das cobranças menos difundidas é a cobrança para proteção do solo, implantada em três países: Bélgica, Holanda e regióes dos Estados Unidos. A base da cobrança é a quantidade de fósforo e/ou nitrogênio nos compostos de fertilizantes. Em nenhuma das situações o real impacto é conhecido, porém os programas apresentam aspectos positivos ao redistribuir a receita às políticas de conservação de solo.

Já a cobrança sobre resíduos é uma das formas mais disseminadas na OCDE. Presente em dezenove países, é encontrada cm três variantes: cobrança sobre o usuário, cobrança sobre disposição e sobre resíduos tóxicos.

A cobrança sobre o usuário domiciliar normalmente é independente da quantidade e / ou toxicidade dos resíduos gerados. A despeito desse fato, alguns países introduziram sistemas que têm alcançado incentivos ${ }^{13}$. Para os usuários industriais, a cobrança é feita em função da quantidade, mas as informaçōes năo permitem maiores inferências. A cobrança sobre disposiçāo incide normalmente sobre a quantidade de resíduos entregues em aterros sanitários e incineradores. Algumas

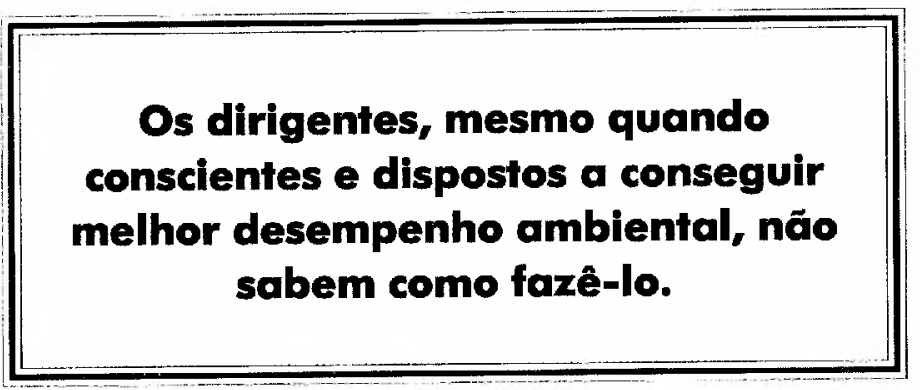

vezes o valor é definido com base no tipo de tratamento necessário para sua disposição de forma segura, como ocorre na Bélgica. Já na Dinamarca, a taxação, iniciada cm 1987, parece indicar que o sistema está afetando diretamente as cmpresas. De 1987 a 1989, o total de residuos gerados diminuiu de $12 \%$. Ainda assim, nāo é possível afirmar com certeza que essa redução seja decorrência direta do emprego desta política. Outros fatores que poderiam estar colaborando para a redução são o aumento do valor da cobrança ao usuário, regulações mais rígidas sobre processamento de resíduos e novos desenvolvimentos tecnológicos. Com relação à cobrança sobre resíduos tóxicos, as taxas instituídas em todos os países, com exceção da Finlândia, săo consideradas ainda muito baixas para criar incentivos efetivos. As receitas auferidas estão sendo canalizadas para a coleta e o
13. DEMAJOROVIC, J. Da politica tradicional de tratamento de lixo à política de gestão de residuos sólidos: as novas prioridades. RAE - Revista de Administração de Empresas. São Paulo, v. 35, ก. 3, p. 88-93. 1995. 
processamento de resíduos e para a recuperaça de áreas contaminadas.

O último tipo de cobrança com base em emissóes é acjuele calcado nas descargas nos recursos hidricos superficiais é subdividido em duas modalidades: uma que remunera os serviços de tratamento de esgotos e outra que recai sobre os lançamentos diretos de efluentes licuidos.

As taxas polos scrviços prestados aos domićlios usualmenle ulilizam como variável para cleilo de cálculo o volume de água consumido. Para as indústrias, ja é possivel localizar sistemas de medição de esgotos lancados. Nos dois casos, quando ocorre a modiçá é razoavel supor que existam incenlivos; na ausência desta, o incentivo, se houver, será indireto.

\section{A melhor estratégia para a consecuçáo de um quadro favorável às empresas e ao meio ambiente, naquilo que depende dos atores privados, é desde já reconhecer que as forças que estão agindo na configuração dos cenários futuros são inexoróveis e existem vastas superfícies de atrito.}

A cobrança pelo despejo direto nos corpos de água ć rcalizada lanto nas indústrias quanto nas residências, sendo a receita direcionada às políticas de controle de qualidade da água e às empresas poluidoras (via cmpréstimo subsidiado). A maioria das expcriências tem demonstrado que, por um lado, os usuários nào são muito sensiveis aos preços praticados; de outro lado, os sistemas de cobrança lôm propiciado receitas capazes de alavancar parte dos investimentos necessários ao controle de poluiçáo e ao desenvolvimento de tecnologias menos intensivas $\mathrm{cm}$ água. Cabe notar que a altcrnativa alemá ilustra que, com criatividade, é possivel desenhar modelos de cobrança que tragam mudanças de comportamento. Nesse país, os consumidores industriais que se adaptam aos padróes definidos pela legislação antes do prazo estipulado são beneficiados com reduçóes de até $75 \%$ na taxa vigente. A Holanda, por sua vez, é um exemplo de que a tradicional opção pela elevação dos valores cobrados pode acarretar incentivos.

A cobranca sobre produlo é uma laxa que incide sobre o preço do bem que cause algum lipo de poluição na fase de produção ou de consumo. O objetivó é estimular alternativas mais eficientes no combate à poluição. Nos países desenvolvidos, as allernalivas de cobrança são inúmeras: automóveis, combustiveis fósseis, agricultura, baterias, óleos lubrificantes, produtos quimicos que atacam a camada de ozónio, embalagens etc. Os estudos, no entanto, informam que são poucos os resultados posilivos em lcrmos de incentivo à mudança de comportamento. De qualquer mancira, nāo se pode negar o papel que desempenham localizadamente, tal como a geração de receitas e a familiarização dos consumidores com os problemas ambientais.

A tributação sobre automóveis ć uma das alternativas que apresenta maior diversidade de formatos e que possui visibilidade perante o público, cmbora os resultados não sejam conclusivos. As diferentes cobranças podem ter por base vários fatores, como, por exemplo, us padróes de emissão, peso, presença de conversores cataliticos e eficiência energética. Dado esse falo, não é de surpreender que os respectivos valores detenham forte dispersāo, desde o patamar de US\$ 40 no Canadá até US\$ 900 na Holanda.

Com relação à cobrança sobre os combuslívcis dos automóveis, os indícios são mais favoráveis. Mesmo não havendo uma medida mais exata para mensurar o impacto da diferenciação de preço entre combustíveis com ou sem chumbo, o incremento na participação de mercado do melhor combustível em termos ambientais - que em alguns países alcança 75\% -- é auspicioso.

$\Lambda$ cobrança sobre os combustiveis de origem fóssil também é promissora. Basta citar dois casos observados na Suécia: no primeiro, o clevado ônus incidente sobre a emissāo de $\mathrm{CO} 2$ está acarretando alteraçốcs nos combustíveis utilizados nas planlas geradoras de calor; no segundo, a taxação dos produtos com enxofre já reduziu cm torno de $30 \%$ a presença desse elemento nos combustíveis.

Outras mudanças no consumo ou nas características de determinados produtos, em certo sentido em razāo de cobranças sustentadas por argumentos ambientais, são: redução do nitrogênio nos fertilizantes na Suécia, redução no uso de CFC nos Estados Unidos, incremento de vasilhames retornáveis na Finlândia e Noruega, redução de sacolas de plás- 
tico na Itália e modificaçoes nos tipos de óleo diesel na Suécia.

Os mercados de licenças negociáveis possibilitam que os diversos alores possam comprar ou vender direitos de poluição. O ponto de partida de operacionalização é o cstabelecimento, pelas autoridades ambientais, do nivel de qualidade ambiental e do volumo tolal de emissóes que poderâo ser lançadas no meio ambiente. A partir daí, define-se o número de licenças que serão distribuídas entre os diversos agentes econômicos. A distribuição das permissóes pode ser foita de duas formas: venda direta pelo poder público ou distribuiçăo gratuita para as diversas empresas, de modo que o preço de compra c venda se ajuste no mercado. Osistema apresenta como principal vantagem um baixo custo de implementação. As experiências concretas, a despeito desse aspecto positivo, estão restritas a quatro países, com destaque absoluto para as iniciativas norte-americanas.

Pon conseguinte, as

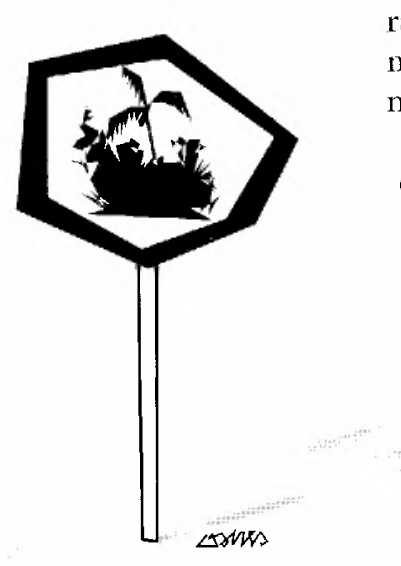
conclusôes sobre a potencialidade do instrumento são frágeis.

Apesar da precariedade de informaçoes, é necessário frisar que essa altemativa vem sendo bastante cstudada e poderá ser incrementada. $O$ otimismo deriva do relativo êxito dos programas levados a cabo pelos Estados Unidos e dos caminhos que estão sendo vislumbrados para superar as falhas iniciais.

As principais áreas abrangidas pelos mercados de licença foram o controle da chuva ácida, controle de CFC, poluiçāo do ar, poluição da água e redução de chumbo na gasolina. O saldo final das experiências é heterogêneo: ao lado de sucessos, como o programa do chumbo, há alguns fracassos, como, por exemplo, a transação das licenças, uma vez que houve um número limitado de transações e comércio a penas entre firmas. A partir da reflexāo dessas múltiplas vivências, as autoridades norte-americanas estão procurando formas de melhorar o funcionamento dos mercados, reduzindo a complexidade de operacionalização e ampliando o escopo dos programas. Cabe destacar as perspectivas ge- radas pelo recém instituído Programa de Controle de Chuva Ácida nos Estados Unidos, que facilita as Iransaçoes de licenças. Fm operação desde 1993, objetiva a redução da emissão de $\mathrm{SO} 2$ em 10 milhões de toneladas, tomando por base os niveis de 1980. As licenças foram distribuidas conforme o padrấo de consumo histórico de combustiveis e balizadas segundo uma taxa de restrição de emissóes. Ficuu estipulado que cada permissão habilitaria a emissão de 1 tonclada de $\mathrm{SO} 2$ por unidade industrial. As empresas que lograrem reduçoos de emissão em um patamar abaixo das autorizaçoes de que dispōem, poderāo vendê-las ou retê-las para outros cxercícios. Sem embargo, o desempenho das propostas será um campo prioritário para futuras pesquisas, seja no que concerne à dinâmica do mercado, seja à capacidade de monitoramento e enforcencht do poder público.

O sistema depósito-restituiçāo consiste no estabelecimento de uma caução associada à compra de um produto cuja restituição é vinculada à devoluçăo da embalagem ou do próprio produto após o seu uso. Seu objetivo é o estimulo da reciclagem e a prevenção da poluiçào. podendo ser iniciativa do governo c/ou das proprias empresas. Quando implementado pelo poder público, a preocupaça ambiental está presente; na outra possibilidade, os fundamentus econômicos são mais vigorosos; $\mathrm{cm}$ ambas os resultados são excelentes. Atualmente, em 16 países da OCDF, existem poucos produtos inseridos en programas do tipo depósito-restituição, com forte participaçáo das garrafas de vidro (retorno de 90 a $100 \%$ de garrafas de cerveja coutras bebidas suaves e de 40 a $80 \%$ para os vinhos elicores), vasilhames de plástico (retorno de $60 \%$ ) e latarias (retorno entre 40 e $90 \%$ ). Tindo em vista tamanho desempenho, é de se esperar o incremento e a expansão para novos produtos, tais como baterias de autonóveis c lâmpadas fluorescentes.

\section{AS EMPRESAS EM FACE DOS INSTRUMENTOS ECONÔMICOS}

A argumentação mais recorrente na literatura sobre os instrumentos de gestão ambiental assevera que as empresas tendem a preferir os instrumentos de comando e controle. A sustentaçāo do posicionamento deri- 
va da percepçào de que as empresas entendem instrumentos econômicos como custos adicionais no processo produtivo $e_{r}$ principalmente, disporiam de maior margem de negociação quando sujeitas ao cumprimento de normas c padrões, seja através de estratégias logais seja através de mecanismos espúrios (por exemplo, corrupção). Os instrumentos económicos, por sua ver, restringiriam a capacidade de "desvios", visto que estariam presentes estímulos financciros para o desempenho ambientalmente mais eficiente.

$\Lambda$ validade dessas iclélas é questionável em funçào das múltiplas posiçōes apresentadas pela classe empresarial. No momento inicial do fortalecimento das politicas ambientais, notadamente após a conferência de Estocolmo, em 1972, verificou-se forte oposição a qualquer forma de regulamentaçào. Tanto as normas e padróes quanto as taxas e demais instrumentos de natureza similar eram entendidos como obstáculos ao processo produtivo. Mais recentemente, no entanto, o discurso do algumas instituiçóes que representam a classe empresarial incorporou o debate sobre a implementação dos instrumentos de gestão ambiental, com uma postura diferente daquela mais freqüentemente encontrada na literatura. Os instrumentos economicos passaram a ser preferenciais, pois propiciariam maior flexibilidade para a gestāo empresarial, enquanto os de comando e controle deveriam apresentar carater complementar ${ }^{1-1}$.

Ainda que esse pensamento tenha sido marcantc no período próximo à conferéncia do Rio de Janeiro, em 1992, o que melhor retrata a realidade ć admitir que as duas linhas mantiveram seus defensores, e que a contenda permanece. Isso tanto é factual, que as diferenças foram novamente salientadas em 1994, dessa feita com grande impacto nas reflexōes sobre as cstratégias cmpresariais, no veículo de divulgaçào da Harvard Businesss School.

A presentando uma visäo bastante provodo o rumo: uma perspectiva empresarial global sobre desemvolvimento e meio ambiente. Rio de Janerro: FGV, 1992, p. $19-30$

15. WALLEY. N., WHITEHEAD, B. It's not easy being green. Harvard Business Review Boston, v. 7 ? n. 3, p. 46-52, 1994.

16. Ver os diversos depoimentos inclusos no segmento "Perspectives" (The challengo of going green) da Harvard Business Review, Boston, v. 72 r. 4, p. 37-50, 1994 a égide dos instrumentos de comando e controle, os caminhos possívcis limitavam-se ao cumprimento ou nào da legrislaçăo. O que os autores salientam é que as decisoes estratégicas não implicavam grandes recursos adicionais, visto que havia espaço paia mudanças sem maiores inovaçôes tecnológicas e gerenciais. Nas condiçóes de concorrência e produção dos anos 90, porém, qualquer avanço significará custos elevados e o comprometimento da viabilidade econômica, como, por exemplo, nas indústrias química e petrolífera.

Nesse novo cenário, os autores também alcrtam para o fato de que os instrumentos econômicos irão adicionar mais um fator de incerteza à tomada de decisão empresarial. Conforme mencionado, quando o foco não está sobre os instrumentos de comando e controle, as empresas ganham flexibilidade. A outra face da moeda é que perdem a sinalização das metas a serem persegutidas. Em condiçóes normais isso não é um obstáculo, pois faz parte do risco a ser assumido pela iniciativa privada. Na área ambiental, tal não se dá, visto o desconhecimento, tanto por parte dos órgãos reguladores quanto das empresas, das imbricaçoes do ciclo dos produtos com o meio ambicnte. Assim, citando pesquisa realizada pela Mckinsey, os autores procuram demonstrar que os dirigentos, mesmo quando conscientes e dispostos a atingir melhores desempenhos ambientais, não sabem como fazê-lo.

$\Lambda$ s opiniôes manifestadas eram tão divergentes da voz corrente que imediatamente surgiram reaçóes contrárias, alertando para o retrocesso que ocorre ${ }^{1 t}$. Para esses analislas, as empresas possuem não só a expertise necessária para responder aos ditames da estrutura regulatória, incluindo-se aí os instrumentos econômicos e os de comando e controle, mas também para transformá-los em oportunidades de negócios. Aqueles que não conseguirem se adaptar acabarão saindo do mercado não devido à intervençāo pública, mas pela própria perda de competitividade diante das exigências dos consumidores, os quais não sancionarão bens e serviços ecologicamente suspeitos.

A distinçăo centra-se, portanto, não no papel dos instrumentos de gestáo ambiental, uma ver que representam apenas um aspecto derivado do principal questionamento, qual seja, a possibilidade de soluçóes do tipo "ganha-ganha" na assimilação da variável ambiental pela gestão empresarial. Colocase em xeque, enfim, a compatibilidade dos objetivos da firma -- lucro, liderança de mercado, sobrevivência etc. - com os objetivos 
ambientais - sustentabilidade, redução de residuos, conscrvação do patrimônio nalural etc.

De um lado, encontram-se aqueles que advogam a exislência, sem margem para dúvidas, de um trade-off entre as decisoes concernente's às necessidades ambientais e empresariais. Por esse prisma, os benelícios gerados pelas iniciativas com preocupacao ambiental nao conseguiriam fazer trente aos custos incorridos. Com o passar do tempo, a estratégia significaria o comprometimento das atividades centrais da organização por conseguinte, estar-se-ia falhando com os acionistas.

De outro lado, estâo os analistas que consideram a dimensão ambiental um novo condicionante interno ao processo decisorio cmpresarial e nà am fator exógeno e antagônico. Diante das transformaçoes da economia mundial, cuja globalizaçio allerou profundamente as caracteristicas da demanda, o descmpenho ambiental teria passado a mlegrar as exigências de qualidade nos bense serviços. Logo, as empresas bem-sucedidas serão aquelas que souberem superar os constrangimentos de curto prazo e aproveitarem as oportunidade's yue estāo surgindo.

Além das questóes atinentes à produção à comercialização, os adeptos da visão que favorece a ênfase no meio ambiente também frisam que essa preocupaça seria uma das modernas responsabilidades da cmpresa com a sociedade. O papel da iniciativa privada não mais se restringiria à geração de riquera, devendo açambarcar as dimonsôes social e ambiental. No contexto, os acionistas representariam uma instância prioritária de prestação de conlas, mas näo exclusiva.

A reflexão sobre as idéas defendidas pelas duas correntes sugere alguns equivocos conceiluais que podem influenciar as estratégias a serem definidas pelas empresas perante os instrumentos de grestão ambicnial. Cabe assinalar, em primeiro lugar, que a facção mais ambientalista apresenta um discurso muito descolado das práticas concretas das empresas. Grande parte do avanço obtido até hoje, conforme apregoam seus opositores, deu-se através de processos de racionalização em um espaço de manobras favorável. Atualmente, os custos tendem a ficar em patamares mais elevados, tanto por conta do aprimoramento nas inovaçöes quanto pelas exigências de governos e cidadãos. Pode-se concluir qué a introduçāo dos instrumentos econômicos será seguida de resistências, pois significará, ao fim e ao cabo, uma pressảo adicional na estrutura de custos. Logicamen- te, se ônus puder ser repassado para os preços, o impacto não será táo sensivel; a questão que fica ê se os consumidores està com disposição para pagar. Esse é um ponto incerto, mesmo sabendo o papel que a demanda vem exercendo nas Iransformaçoes no passiado recenle, ao optar por produtos mais caros nas com processos produlivos ambientalmente saudaveis. Como bem lembra Frances Caimcross, editora de meio ambiente do somanário the iforomisl, as informagoes que os consumidores recebem são erraticas demais, criando flutuagoes no padrao de consumo que acabam impedindo gue haja coevencia duradoura na ação das firmas ${ }^{17}$. En funça dessa coraclerística, os empresários cerlamente demonstrarāo algumas restriçóes à instituicáo dos instrumenlos economicos.

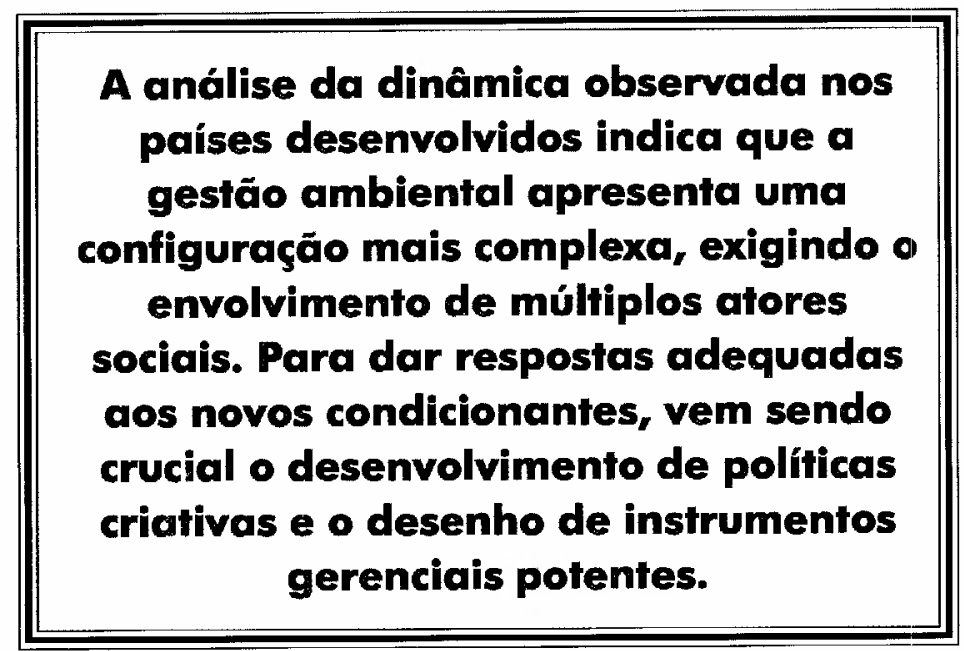

Jâ a corrente mais cética cai no erro de menosprezar dois pontos fulcrais: a relevância da temática ambiental nesté fim de século e o novo papel requerido para as empresas. Não há como desconhecer que o assunto meio ambiente irá permear as atividades publicas - privadas, com fortes desdobramentos no campo dos negócios. $F$ isso tratando-se ou não de políticas "ganha-ganha". O que so quer dizer é que poderá haver ineficiências no desenho dos novos instrumentos econômicos e dos de comando e controle, como por exemplo, através de barreiras nãotarifárias no comércio internacional's; poderá haver grandes indefiniçócs em razão do desconhecimento, nas nāo existirá alternativa: as empresas devera estar preparadas para transitar na realidade mais intrincada, $e$ agora prestando contas para um universo maior.
17. CAIRNCROSS, F, Meio ambiente: custos e beneficios. São Paulo: Nobel, 1992.

18. GUIMARÃES, P. Comércio internacional e desenvolvimento sustentável: condicionantes para a ação empresarial. $R A E$ Revista de Administração de Empresas, São Paulo, v. 34 . n. 5, p. 6-12. 1994 


\section{PONCLUSOES}

A análise da dinâmica observada nos países desenvolvidos indica que a gestão ambiental apresenta uma configuração mais complexa, exigindo o envolvimento de múltiplos atores sociais. Para dar respostas adequadas aos novos condicionantes, vem sendo crucial o desenvolvimento de políticas criativas e o desenho de instrumentos gerenciais potentes. Nesse contexto, um movimento visível é a ênfase na utilização crescente de instrumentos econômicos.

Os resultados dessa política ainda não lograram todos os objetivos almejados, o que não constitui surpresa, dado o caráter inovador das propostas. De fato, o balanço das iniciativas de aplicaçāo prática informa que os instrumentos econômicos não estão desempenhando a contento sua função básica, qual seja, incentivar a mudança de comportamento dos usuários, diretos e indiretos, dos recursos ambientais. Ao mesmo tempo, em algumas situações têm gerado custos adicionais para os consumidores, as empresas e o próprio poder público.

Cabe reconhecer, porém, que apesar dos percalços existem avanços substantivos que estão contribuindo para melhorar a qualidade ambiental. A geração de receitas que reverlem para programas ambientais, a pesquisa e o desenvolvimento de novas tecnologias e a influência nos hábitos e valores de consumidores dão uma idéia do grande potencial que os instrumentos econômicos possuem.

Pelo lado do setor empresarial, é forçoso notar que na nova vertente as amarras do sctor público não são tăo intensas, dando maior flexibilidade para as decisōes empresariais. Também está patente que segmentos empreendedores privados estāo sabendo aproveitar os novos nichos de mercado que a realidacte cria. O sucesso de sistemas de depósito-restituição de alguns produtos, assim como diferentes arranjos organizacionais na prestação de serviços públicos - privatização, terceirização etc. - demonstram cabalmente que há oportunidades concretas para o mundo dos negócios.

É certo que as afirmaçōes valem mais para os paises desenvolvidos, mas o processo de globalização tende a envolver as demais economias. No caso brasileiro, é possivel localizar iniciativas convergentes, mas as circunstâncias nacionais trazem algumas preocupaçöes.
Do ponto de vista da ação do setor público, a debilidade do aparato administrativo estatal compromete a implantação de instrumentos econômicos, uma vez que políticas fundamentais como o licenciamento, monitoramento e enforcement provavelmente não serão corretamente desempenhadas.

Pela óptica do setor privado, verifica-se otimismo apenas em relação à expansão dos mercados para os denominados produtos "verdes" 19 . O entusiasmo não é o mesmo quando entra em pauta o tema dos instrumentos econômicos, existindo predominância de uma visão simplista em que são considerados como um "imposto" adicional que deve ser cvitado. A resistência até é compreensível, em face das distorções dos sistemas fiscal e tributário. Deve-se notar, contudo, que os instrumentos econômicos de gestão ambiental distinguem-se dos instrumentos de política econômica: seu objetivo é disciplinar o uso dos recursos naturais e controlar a qualidade ambiental, e não atuar visando a finalidades redistributivas ou estabilizadoras. Ou scja, as arenas de discussăo sâo distintas e não podem ser confundidas.

A melhor estratégia para a consecuçāo de um quadro favorável às empresas e ao meio ambiente, naquilo que depende dos atores privados, é desde já reconhecer que as forças que estão agindo na configuração dos cenários futuros sāo inexoráveis e existem vastas superficies de atrito. A parlir disso, as cmpresas devem buscar canais para o diálogo com o poder público, procurando uma estruturação adequada dos instrumentos de gestão ambiental, $\mathrm{c}$ não reivindicar a simples redução da inlervenção estatal. Tâl posicionamento esquece que o mercado, por si só, năo interioriza os custos e benefícios ambientais. É imprescindível, pois, que fique bem claro que as empresas podem se antecipar e proceder a ajustes, mas a chave para os resultados será o perfil da regulação pública. Se no passado ocorreram problemas no relacionamento entre os órgãos regulatórios e as empresas, muito se deveu, entre outros fatores, aos preconceitos das partes e ao desconhecimento dos impactos ambientais derivados da atividade produtiva. Certamente a superação desses fatores não eliminará os conflitos; todavia abrirá novos espaços para a negociação permanente, o que não deixa de ser um desafio para todos os participantes. . competição. Revista de Administraçắo, São Paulo, v. 30, n 1, p. 32-45, 1995
Artigo recebido pela Redação da RAE em maio/1995, avaliado e aprovado para publicação em julho/1995. 